
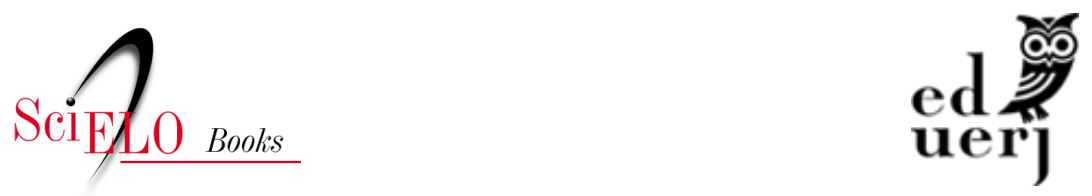

\title{
Capitulo 3 - Promoção da alimentação adequada e saudável na Atenção Básica: avançose desafios
}

\author{
Ana Carolina Feldenheimer da Silva \\ Patrícia Constante Jaime
}

\section{SciELO Books / SciELO Livros / SciELO Libros}

SILVA, A. C. F., and JAIME, P. C. Promoção da alimentação adequada e saudável na Atenção Básica: avanços e desafios. In.: SILVA, A. C. F., MOTTA, A. L. B., and CASEMIRO, J. P., eds. Alimentação e nutrição na atenção básica: reflexões cotidianas e contribuições para prática do cuidado [onine]. Rio de Janeiro: EDUERJ, 2021, pp 58-76. ISBN: 978-65-87949-11-6. https://doi.org/10.7476/9786587949116.0004.

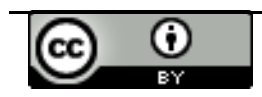

All the contents of this work, except where otherwise noted, is licensed under a Creative Commons Attribution 4.0 International license.

Todo o conteúdo deste trabalho, exceto quando houver ressalva, é publicado sob a licença Creative Commons Atribição 4.0.

Todo el contenido de esta obra, excepto donde se indique lo contrario, está bajo licencia de la licencia Creative Commons Reconocimento 4.0. 


\section{Capitulo 3 \\ Promoçáo da alimentaçáo adequada e saudável na Atenção Básica: avanços e desafios}

Ana Carolina Feldenheimer da Silva

Patrícia Constante Jaime

Ao pensarmos a promoção da alimentação adequada e saudável (PAAS) como elemento de produção do cuidado em saúde no âmbito da Atenção Básica, necessariamente essa questão nos remete a alguns princípios estruturantes. $\mathrm{O}$ primeiro deles é o reconhecimento da alimentação e da nutrição como requisitos básicos para promoçáo e proteçáo da saúde, constituindo-se como alguns dos seus fatores determinantes e condicionantes, como afirma o artigo 3. ${ }^{\circ}$ da Lei n. ${ }^{\circ}$ 8.080, Lei Orgânica da Saúde (Brasil, 1990). A Organização Mundial de Saúde (OMS) aponta para a necessidade de melhoria nos padróes mundiais de alimentação para prevenção, em especial, de doenças crônicas não transmissíveis (Who, 2003).

Além da perspectiva da prevenção de agravos à saúde relacionados a fatores dietéticos ou ao estado nutricional do indivíduo, a alimentação é reconhecida como um elemento essencial para promoção da saúde e do bem-estar e como um direito social. No Brasil, assim como a saúde, a alimentação saudável é assegurada no artigo 6..$^{\circ}$ da Constituição Federal entre os direitos sociais individuais e coletivos. Como os direitos humanos são indivisíveis, interdependentes e inter-relacionados em sua realização, podemos compreender como a produçáo do cuidado em saúde está, indelevelmente, imbricada à promoção da alimentação saudável. 
A garantia da saúde depende de açóes de diversas áreas que garantam a realização dos demais direitos humanos, entre eles o direito à alimentação adequada, que constitui a base para a plena saúde em seu conceito mais amplo (Brasil, 2010).

Outro princípio importante a ser resgatado, como pontuado pela Política Nacional de Alimentação e Nutrição (PNAN) (Brasil, 2012a), é o da alimentação como elemento de humanização das práticas de saúde:

A alimentação expressa as relações sociais, valores e história do indivíduo e dos grupos populacionais e tem implicações diretas na saúde e na qualidade de vida. A abordagem relacional da alimentação e nutrição contribui para o conjunto de práticas ofertadas pelo setor saúde na valorização do ser humano para além da condição biológica e o reconhecimento de sua centralidade no processo de produção de saúde.

Dessa forma, as ações de alimentação e nutrição devem ser desempenhadas de forma transversal às ações de saúde, em caráter complementar e com formulação, execução e avaliação dentro das atividades e responsabilidades do sistema de saúde com vista à garantia de direitos sociais (Brasil, 2012a). O universo interdisciplinar e colaborativo da Atenção Básica (AB), sua organização voltada ao cuidado continuado e integral, sua relação estreita com o território, sua vocação cultural e o estabelecimento de vínculos entre serviço e usuário propiciam um espaço exemplar de exercício da promoção da alimentação adequada e saudável, ação intrínseca ao cuidado em saúde, devendo compor o cardápio de atividades desempenhadas pelos profissionais que atuam em todos os pontos de atenção, em especial a $\mathrm{AB}$.

Este capítulo tem como objetivo discutir o paradigma da promoção da alimentação adequada e saudável, apresentar seus principais marcos e contextualizar as açóes de PAAS no cuidado à saúde e na prática cotidiana das equipes de $\mathrm{AB}$. 


\section{O paradigma da promoçáo da alimentaçáo adequada e saudável}

Alimentação adequada e saudável é um conceito em evolução. Por muito tempo, foram valorizados atributos relacionados à composição nutricional de alimentos e da dieta, ou seja, quais nutrientes caracterizam a alimentação e como eles poderiam expor indivíduos e comunidades a riscos para determinadas doenças. Com esse recorte, é um conceito com abordagem preventivista que se centra nos nutrientes, nas propriedades bioquímicas dos alimentos e seu efeito no corpo humano, compreendendo a alimentação saudável como uma equaçáo simplista, composta por elementos imutáveis e aplicáveis como uma regra geral para todas as pessoas (Pellicioni e Pellicioni, 2007; Boog, 2008; Garcia, 1997) .

Tal visáo reducionista sobre alimentação saudável passou a ser questionada por sua limitada capacidade de explicaçáo da relação biológica entre alimentaçáo e saúde, uma vez que se acumularam evidências de que nutrientes isolados explicam pouco a ocorrência de doenças. Também porque não leva em conta uma visão sistêmica da alimentação, que considera o conjunto de etapas pelas quais os alimentos passam, desde sua produção, extração, processamento, distribuição e comercialização, até o consumo humano, no final dessa cadeia de processos sociais (Carvalho, Luz e Prado, 2011).

Quando recomendaçôes alimentares são centradas em nutrientes e desconsideram as diversas dimensôes que envolvem a alimentaçáo, elas encontram sustento no paradigma biomédico, o que reflete nas práticas de saúde que envolvam educação alimentar e aconselhamento nutricional. É preciso reconhecer a possibilidade de integração de conhecimentos - biológico-nutricional e a abordagem das ciências humanas e sociais. Incorporar novas dimensōes ao conceito de alimentação adequada e saudável potencializa uma prática em saúde interdisciplinar (Freitas, Minayo e Fontes, 2011).

Percebe-se, assim, que uma visão ampliada de alimentação adequada e saudável envolve saberes e práticas de diversos atores e 
campos do conhecimento que se relacionam com a alimentação e o sistema alimentar. Dessa forma, torna-se importante compreender não só o que se come, mas também as formas de produção (modelos de agricultura e pecuária) e de acesso aos alimentos (políticas de abastecimento e comercialização, em diferentes modalidades), a sustentabilidade dos sistemas alimentares e os aspectos da comensalidade, ou seja, os modos de comer de indivíduos e coletividades que estão intrinsecamente relacionados à cultura (Monteiro et al., 2015).

\section{Marcos normativos da PAAS - expressos nas políticas públi- cas e documentos oficiais}

No Brasil, a PAAS está presente em uma série de marcos normativos oficiais, que apresentam conceitos e diretrizes para sua ação, tendo sua importância reconhecida e repensada há quase duas décadas. Na primeira versão da PNAN (Brasil, 1999), a Promoção da Alimentação Saudável foi apresentada como uma de suas sete diretrizes. Em 2006, a Política Nacional de Promoção da Saúde (Brasil, 2006) apresenta a alimentação saudável como uma ação específica de atuação da promoção da saúde no Sistema Único de Saúde (SUS).

Um importante avanço nos marcos legais brasileiros foi a Emenda Constitucional n. ${ }^{\circ}$ 64/2010, que modificou o art. $6 .^{\circ} \mathrm{da}$ Constituição de 1988 para incluir o direito à alimentação no rol dos direitos sociais:

Art. 6. ${ }^{\circ}$ - São direitos sociais a educação, a saúde, a alimentação, o trabalho, a moradia, o lazer, a segurança, a previdência social, a proteção à maternidade e à infância, a assistência aos desamparados, na forma desta Constituição.

Em 2011, na revisão da PNAN, a promoção da alimentação saudável ganhou um novo termo, sendo definida como Promoção 
da Alimentação Adequada e Saudável - o conceito de adequação da alimentação foi agregado ao conceito de saudável, entendendo que a alimentaçáo deve ser saudável, mas adequada ao contexto socioeconômico.

A PAAS é tema recorrente nos documentos de referência do campo da Segurança Alimentar e Nutricional. Todos os relatórios das Conferências Nacionais de Segurança Alimentar e Nutricional (total de cinco até o ano de 2017) apresentam a alimentação adequada e saudável como um direito humano e que para sua efetivação são necessárias açôes em diferentes setores, como a produção de alimentos, regulação, oferta, disponibilidade, ambientes protetores e orientaçóes dos profissionais de saúde.

O Marco de Referência de Educação Alimentar e Nutricional para as Políticas Públicas afirma que é necessária uma valorização em torno da PAAS para que ele ganhe o espaço proporcional à sua importância. Na prática do cuidado, açóes de PAAS são relegadas a um segundo plano ou simplesmetne ignoradas como uma possibilidade de atuação de todos os membros da equipe de saúde, sendo atribuiçáa do nutricionista. Toda a equipe de $\mathrm{AB}$ pode $\mathrm{e}$ deve conhecer as diferentes práticas alimentares da população que assiste, bem como os determinantes, suas consequencias na saúde dos indivíduos e a compreensão de que os resultados esperados das práticas de EAN, como melhoria dos hábitos alimentares ou do estado de saúde como um todo, só serão alcançados, no médio ou longo prazos, com práticas permanentes e significativas a quem elas se destinam (Brasil, 2012b).

O documento oficial mais recente que apresenta o conceito de PAAS é o Guia alimentar para a população brasileira (Brasil, 2014a): 
A alimentação adequada e saudável é um direito humano básico que envolve a garantia ao acesso permanente e regular, de forma socialmente justa, a uma prática alimentar adequada aos aspectos biológicos e sociais do indivíduo e que deve estar em acordo com as necessidades alimentares especiais; ser referenciada pela cultura alimentar e pelas dimensôes de gênero, raça e etnia; acessível do ponto de vista físico e financeiro; harmônica em quantidade e qualidade, atendendo aos princípios da variedade, equilíbrio, moderação e prazer; e baseada em práticas produtivas adequadas e sustentáveis.

O Guia alimentar para a população brasileira, publicado em 2014, apresenta um novo paradigma para a PAAS. A versão anterior apresentava suas recomendaçôes com base na divisão de porçôes dos grupos de alimentos organizados de acordo com as características de composição destes, dividindo as recomendações em sete diretrizes (os alimentos saudáveis e as refeiçôes; cereais, tubérculos e raízes; frutas, legumes e verduras; feijóes e outros alimentos vegetais ricos em proteínas; leite e derivados, carnes e ovos; gorduras, açúcares e sal; e água) e duas diretrizes especiais (atividade física e qualidade sanitária dos alimentos) (Brasil, 2006a).

A atual versão do guia apresenta suas recomendaçóes de acordo com a extensão e o propósito do processamento de alimentos e seu consequente impacto para a saúde. Além da orientaçáo sobre a alimentação em si, o guia discute aspectos da comensalidade, considerados como promotores da saúde e identificados os potenciais obstáculos para a adesão às recomendaçóes com claro reconhecimento dos determinantes sociais e ambientais das práticas alimentares (Brasil, 2014a). 
Quadro 1. Quatro recomendaçóes e uma regra de ouro do Guia alimentar para a populaçāo brasileira

1. Faça de alimentos in natura ou minimamente processados a base de sua alimentaçáo. Alimentos in natura ou minimamente processados, em grande variedade e predominantemente de origem vegetal, são a base de uma alimentação nutricionalmente balanceada, saborosa, culturalmente apropriada e promotora de um sistema alimentar socialmente e ambientalmente sustentável.

2. Utilize óleos, gorduras, sal e açúcar em pequenas quantidades ao temperar e cozinhar alimentos e criar preparaçóes culinárias. Desde que utilizados com moderação em preparaçôes culinárias com base em alimentos in natura ou minimamente processados, óleos, gorduras, sal e açúcar contribuem para diversificar e tornar mais saborosa a alimentação sem torná-la nutricionalmente desbalanceada.

3. Limite o uso de alimentos processados, consumindo-os, em pequenas quantidades, como ingredientes de preparaçóes culinárias ou como parte de refeiçóes baseadas em alimentos in natura ou minimamente processados. Os ingredientes e métodos usados na fabricação de alimentos processados - como conservas de legumes, compotas de frutas, queijos e pães - alteram de modo desfavorável a composição nutricional dos alimentos dos quais derivam. 
4. Evite alimentos ultraprocessados. Devido a seus ingredientes, alimentos ultraprocessados - como biscoitos recheados, "salgadinhos de pacote", refrigerantes e "macarrão instantâneo" - são nutricionalmente desbalanceados. Por conta de sua formulação e apresentação, tendem a ser consumidos em excesso e a substituir alimentos in natura ou minimamente processados. Suas formas de produção, distribuição, comercialização e consumo afetam de modo desfavorável a cultura, a vida social e o meio ambiente.

5. A regra de ouro: prefira sempre alimentos in natura ou minimamente processados e preparaçôes culinárias a alimentos ultraprocessados Opte por água, leite e frutas no lugar de refrigerantes, bebidas lácteas e biscoitos recheados; não troque a "comida feita na hora" (caldos, sopas, saladas, molhos, arroz e feijão, macarronada, refogados de legumes e verduras, farofas, tortas) por produtos que dispensam preparação culinária ("sopas de pacote", "macarrão instantâneo”, pratos congelados prontos para aquecer, sanduíches, frios e embutidos, maioneses e molhos industrializados, misturas prontas para tortas), e fique com sobremesas caseiras, dispensando as industrializadas.

Fonte: Brasil (2014a).

Uma vez que a alimentação envolve a escolha e a combinação de diferentes alimentos - e a este produto chamamos "comida", que é marcada por tradiçóes, hábitos e cultura -, o Guia alimentar complementa suas recomendaçóes com orientaçóes detalhadas sobre como combinar alimentos e criar refeiçóes saudáveis, culturalmente referenciadas e saborosas no café da manhã, almoço, jantar e nas pequenas refeiçóes, levando em conta o padrão de consumo alimentar da população brasileira de todas as regióes do país, baseadas essencialmente em alimentos in natura e minimamente processados 
(com exceção dos queijos), que são apresentados nos seguintes grupos: feijōes; cereais (arroz, milho e trigo); raízes e tubérculos; legumes e verduras; frutas; castanhas e nozes; leite e queijos; carnes e ovos (carne vermelha, aves, pescados e ovos); e água. Todos com suas características nutricionais, opçóes de substituição, modos de preparo e consumo.

Sobre "o ato de comer e a comensalidade", o guia aponta que a alimentação adequada e saudável é influenciada por circunstâncias que envolvem o tempo e a atenção dedicados à refeição, o ambiente onde ela é realizada e a importância/benefícios da partilha de refeiçôes. São apresentadas três orientaçôes principais nesse sentido: comer com regularidade e atenção, comer em ambientes apropriados e comer em companhia. Percebe-se que são mensagens simples, não prescritivas, que buscam apoiar a adoçáo de comportamentos saudáveis em alimentação.

Ao incluir um capítulo intitulado "A compreensão e a superaçáo de obstáculos", o Guia alimentar considera como potenciais barreiras e facilitadores para a alimentação saudável não somente as questôes inerentes ao indivíduo, às famílias e comunidades, mas também ao ambiente alimentar e às políticas públicas. São elencados cinco obstáculos para adoção de práticas alimentares saudáveis: informação (acesso à informação sobre alimentação e saúde), oferta (oferta de alimentos no ambiente alimentar), custo (custo das refeiçôes dentro e fora do domicílio), habilidades culinárias (habilidades transmitidas entre geraçóes que possam favorecer a prática de cozinhar), tempo (tempo dedicado à alimentaçáo) e publicidade (exposição às propagandas e publicidade de alimentos).

Oliveira e Amparo-Santos (2017) fazem uma análise do Guia alimentar apontando que, além das evidentes diferenças na abordagem sobre alimentação, a própria estrutura gráfica do guia, suas imagens em fotografias ou esquemas, demonstra importantes aspectos da alimentação, como subjetividades relacionadas ao ato de 
comer, as histórias de vida, vínculo, relações familiares e a dimensão local, cultural, regional e global envolvidos nesse padrão dietético.

A Política Nacional de Promoção da Saúde (publicada em 2014) apresenta o tema da PAAS como um dos temas prioritários, pela alimentação ser um direito fundamental garantido pela Constituição Federal desde 2010, pelo caráter intersetorial da PAAS, pela capacidade de se articular e ser trabalhada em diversos setores e programas governamentais e pela relação direta da PAAS para enfrentamento da obesidade e das doenças crônicas náo transmissíveis (Malta et al., 2018).

O Guia alimentar para crianças brasileiras menores de dois anos (Brasil, 2019) reforça o proposto pelo Guia alimentar para a população brasileira e apresenta novos princípios, todos alinhados e refletindo a PAAS em diversos contextos e com uma abordagem focada nas necessidades das crianças menores de dois anos e sua família: "a saúde da criança é prioridade absoluta e responsabilidade de todos"; "o ambiente familiar é espaço para a promoção da saúde"; "os primeiros anos de vida são importantes para a formação dos hábitos alimentares"; "o acesso a alimentos adequados e saudáveis e à informação de qualidade fortalece a autonomia das famílias"; "a alimentação é uma prática social e cultural"; "adotar uma alimentação adequada e saudável para a criança é uma forma de fortalecer sistemas alimentares sustentáveis"; e "o estímulo à autonomia da criança contribui para o desenvolvimento de uma relação saudável com a alimentação”.

\section{A PAAS e a prática interprofissional na Atenção Básica em Saúde}

Embora ainda tenhamos na formação dos profissionais de saúde e na prática cotidiana do SUS a marca do uniprofissionalismo, que conduz à fragmentação do cuidado, saberes e práticas (Feuerwerker et al., 2013), é crescente o esforço no sentido do 
trabalho em equipe, colaborativo com foco no usuário, nas suas necessidades de saúde e da populaçáo, e não mais nos profissionais e seus domínios de conhecimento.

A qualificação das açôes de promoção da alimentação saudável como elemento do cuidado em saúde na $A B$ passa pelo reconhecimento da dificuldade dos profissionais de saúde em incorporarem, no seu cotidiano, os pressupostos para uma prática interprofissional relacionada à alimentação, seja por questóes de formação ou relacionadas ao processo de organizaçáo do trabalho. Por outro lado, as dificuldades vividas pelos profissionais podem ser resultado do próprio conteúdo das recomendaçôes em alimentaçáo - quando materializadas sob a forma de guias alimentares tradicionais, nutriente-centrados -, o que dificulta sua incorporação ao cotidiano das múltiplas e complexas questôes que envolvem a alimentação e nutrição no trabalho em saúde.

Nesse sentido, no que se refere à organizaçáo dos serviços de saúde, a $\mathrm{AB}$ é considerada espaço privilegiado, apesar de não ser o único, para o desenvolvimento de açóes de PAAS. As açóes podem ser feitas pelo conjunto dos profissionais que atuam nesse ponto da Rede de Atenção à Saúde. Para tanto, é necessário operacionalizar a temática da PAAS nos encontros possíveis entre núcleo e campo de prática profissional, como exposto por Campos (2000): núcleo como uma aglutinação de conhecimentos que demarca a identidade de uma área de saber e de prática profissional; e o campo como um espaço de limites imprecisos onde cada disciplina e profissão buscam, em outras, apoio para cumprir suas tarefas teóricas e práticas. De tal modo que a inclusão de uma lógica de trabalho na $\mathrm{AB}$ que envolva prática colaborativa interprofissional amplia o cardápio de possibilidades para a inclusão de práticas promotoras da saúde nos territórios atendidos, dentre as quais a ampliação da PAAS, assumindo que cada profissional contribuirá com sua perspectiva em núcleo e em campo. 
Como exposto, a adoção de uma visão ampliada de alimentação saudável, que considera os aspectos biológicos, psicológicos, sociais, culturais, ambientais e sistêmicos que envolvem o binômio homem-alimento e o ato de comer, propicia uma rica experiência de atuação interprofissional, que pode ser aprimorada com a prática do matriciamento, educação permanente e com a apropriação da temática da alimentação adequada e saudável por todos os profissionais.

Mas é preciso considerar que, além das questôes intrínsecas do processo de trabalho dos profissionais na $\mathrm{AB}$, a prática da promoção da alimentação adequada e saudável depende de uma série de açóes e estratégias, que, isoladas, apresentam efetividade limitada, mas que, aliadas e alinhadas, têm a capacidade de fortalecer as açôes e gerar resultados mais eficazes e duradouros. As açôes são comumente focadas no indivíduo, deixando a cargo deste toda a responsabilidade na adoção de hábitos saudáveis e ignorando o meio e as condiçóes no qual ele está inserido.

É extremamente importante entender que as açôes podem ser operacionalizadas no nível individual e no coletivo, que uma ação não invalida a outra e que o empoderamento dos indivíduos, para que este faça as melhores escolhas e assuma seus riscos, é um dos objetivos primordiais para as práticas de PAAS, focando na ampliação do repertório para fortalecer o autocuidado.

$\mathrm{A} A \mathrm{AB}$ é um terreno fértil e primordial para a PAAS, mas as ações não devem se restringir a esse lócus de ação. Todos os pontos da Rede de Atenção à Saúde devem praticar a PAAS, com especial atenção aos ambulatórios de especialidades e hospitais, atuando de acordo com as especificidades e alinhados com as recomendaçóes do Guia Alimentar e as diretrizes clínicas e protocolos terapêuticos para cada agravo.

Ao se planejar e executar açóes de PAAS na AB, é importante saber quem são os interlocutores e como os modelos propostos de atenção à saúde respondem às práticas de promoção da saúde. Estudo realizado na cidade de Pelotas constatou que o público 
que tinha maior probabiliade de ser exposto a atividades de PAAS eram mulheres, idosos, pessoas com doenças crônicas, pessoas com autopercepção negativa da dieta e usuários acompanhados pela Estratégia de Saúde da Família, brancos e pessoas com ensino médio ou superior, e apontava para a inequidade na oferta das açôes, atentando ao desenvolvimento de estratégias para que mais grupos sejam cobertos pelas açóes (Lindemann e Mendoza-Sassi, 2016). A tentativa de ampliaçáo do público-alvo das açóes demanda esforços da equipe de $\mathrm{AB}$, mas também aumenta a chance de resultados positivos e mudanças substancias no âmbito das famílias.

\section{O território como espaço para a PAAS}

O território é um conceito-chave quando pensamos nas organizaçôes das açóes de saúde, e dentro delas, as açóes de PAAS. Atualmente, todos os pontos de atençáo das RAS têm sua clientela delimitada pelo território, que pode variar de setores de bairros a cidades ou uma regional de saúde inteira. $\mathrm{Na} A B$, o território é um conceito estruturante e que impacta na organização da oferta das açôes. Para a organização das açôes de PAAS, o território deve ser encarado para além do espaço físico estático, representado por um mapa, que delimita as ruas nas quais residem os usuários da unidade $\mathrm{A}$ ou $\mathrm{B}$ e que

o espaço deve ser considerado como uma totalidade, a exemplo da própria sociedade que lhe dá vida [...] um conjunto de funçôes e formas que se apresentam por processos do passado e do presente [...] o espaço se define como um conjunto de formas representativas de relaçóes sociais do passado e do presente e por uma estrutura representada por relaçóes sociais que se manifestam através de processos e funçôes (Saquet e Silva, 2011). 
O território é um espaço vivo, composto por relaçóes, afetos, interaçóes e que esses elementos precisam ser considerados no planejamento e execução das ações de PAAS. A relação ativa com o território, desde o mapeamento de pontos de interesse que facilitam ou que dificultam a alimentação adequada e saudável pode ser um primeiro passo para a ação. Outro ponto importante é o mapeamento de possíveis parceiros para desenvolver e potencializar as açóes. $\mathrm{O}$ espaço da promoção da saúde deve ser compreendido como o espaço da vida das pessoas e náo apenas a sala de reunióes da Unidade de Saúde.

A busca, no território, por parceiros de outros setores que não apenas os da saúde, tende a facilitar e enriquecer as açóes de PAAS. A educação e o serviço social, por meio de açôes e programas como o Programa Saúde na Escola, Programa Bolsa Família e outras iniciativas locais, tendem a ser os parceiros mais clássicos e óbvios para a concretização da intersetorialidade, mas apenas essas articulaçóes podem ser insuficientes, necessitando parcerias com outros setores, como os produtores de alimentos, donos de pequenos comércios dispostos a ampliar a oferta de alimentos in natura a preços acessíveis, cozinhas comunitárias, restaurantes populares e ambulantes que atuam no entorno de escolas, que podem ser acessados, sensibilizados e parceiros reais nas açóes de PAAS.

Embora a escola seja um espaço entendido como privilegiado para as açóes, Camozzi et al. (2015) apontam para o fato de que as atividades devem ser qualificadas, e não focadas apenas na capacitação dos professores ou melhoria do cardápio da alimentação escolar, que costuma ser observada ou pelo ponto de vista biológico da alimentação ou como uma ação de cunho assitencial. Para a PAAS, na escola toda a comunidade deve ser mobilizada profissionais docentes e náo docentes, pais, parceiros e estudantes - a fim de que o tema seja introduzido de forma transversal no currículo e na realidade escolar. Para que se alcancem desfechos positivos nas açóes desenvolvidas, é necessário o investimento em 
práticas inovadoras, de longo prazo e alinhadas às realidades locais (Ramos, Santos e Reis, 2013).

$O$ ensino superior (faculdades e universidades) também compóe o território de responsabilidade da $\mathrm{AB}$, mas costuma ser sistematicamente ignorado. Esse público pode ser estratégico, uma vez que os frequentadores desses espaços não costumam frequentar as unidades de $A B$. Muitos estudantes universitários têm este como o primeiro momento distante de sua família, e as práticas desse período são um primeiro ensaio para a vida adulta (Bussato et al., 2015).

\section{Desafios para a PAAS:}

\section{Determinantes sociais da saúde}

As questóes sociais interferem diretamente nas escolhas e comportamento alimentares dos indivíduos e coletividades. As mudanças sociais e as novas conformaçóes familiares (monoparentais, homoafetivas, separadas ou com configuraçóes distintas das "tradicionais") aliadas a outros fatores "sociais", como pobreza, educação, violência, poluição, discriminação, criminalidade, religião, trabalho, renda, acesso à serviços de saúde, transporte, acesso à água, saneamento, são determinantes da alimentação dos indivíduos e comunidades.

Além dos indicadores clássicos propostos para avaliar as desigualdades e iniquidades em saúde, é importante levar em consideração que a sociedade brasileira é composta de várias ancestralidades (índios, africanos, europeus, árabes, judeus etc.), e, atualmente, os refugiados oriundos da África, Países Árabes e América Latina, resultando em uma grande miscigenação de valores sociais e culturais que geraram a identidade do povo brasileiro, uma identidade única, com grande variabilidade regional e que náo pode ser comparada à outras de maneira simplista, compondo um tecido social 
complexo e único. Cada indivíduo possui trajetórias individuais e familiares únicas que resultam em valores, culturas, expressóes de afeto, símbolos e identidades que devem ser considerados.

A PAAS vai muito além de escolhas e práticas individuais e não está relacionada somente às responsabilidades do setor saúde, passa necessariamente pela garantia de condiçôes sociais e econômicas que criem uma base favorável à adoção de estilos de vida saudável. Sob esta ótica, é importante avaliar a oferta e o acesso da população atendida aos alimentos saudáveis (alimentos in natura e minimamente processado) e os alimentos ultraprocessados (que devem ser evitados). Essa avaliação deve levar em consideração todas as possibilidades de consumo de alimentos (refeiçóes feitas em casa e refeiçóes fora do domicílio: trabalho, escolas, restaurantes populares etc.) e discutir e apontar quais são as melhores escolhas nos diferentes cenários e possibilidades.

\section{Controle social e participação popular}

As equipes de $\mathrm{AB}$ consomem parte preciosa do seu tempo planejando e executando as açóes de promoção, e, muitas vezes, o resultado é aquém do esperado, gerando angústia e frustração. Muito já foi abordado anteriormente sobre questóes e fatores que precisam ser levados em consideração. Um deles, crucial para a promoção da saúde é a participação dos usuários em todas as etapas do processo e não apenas como sujeitos passivos da ação.

O levantamento de demandas reais sobre alimentação é uma estratégia que tende a qualificar o debate e gerar identidade entre os usuários do SUS e os temas abordados. O objetivo deve ser gerar uma aprendizagem significativa, socialmente referenciada e que gere uma mudança real de comportamento dos indivíduos. Promover avaliaçóes periódicas, participativas e dialogadas também pode ser um instrumento eficaz de participação e escuta, desde que gere 
mudanças efetivas e não seja apenas parte do protocolo de realização das atividades ou mera formalidade exigida pela gestão.

Necessidade de politicas públicas nos diferentes setores (da produção ao prato) para garantir o preconizado na Saúde

Para que a PAAS se efetive, é necessária a adoção e defesa de políticas públicas em diferentes setores além da saúde (educação, assistência social, trabalho, renda, saneamento, abastecimento, cultura etc.). O SUS tem um papel central nas ações de promoção da saúde e promoção da alimentação adequada e saudável, e sua manutenção, fortalecimento, financiamento adequado são cruciais, sempre com foco na universalidade das ações.

Outras açóes e programas e políticas, como o Programa Bolsa Família, Programa de Alimentação do Trabalhador, Programa Nacional de Alimentação Escolar, Programa de Aquisição de Alimentos e os Planos Nacionais de Saúde e de Segurança Alimentar e Nutricional, precisam ser fortalecidos e focados na garantia da Promoção da Alimentação Adequada e Saudável e do Direito Humano à Alimentação Adequada e Saudável.

As açóes de PAAS podem ser exercidas por diversos setores, respeitando sua vocação e atribuição. $\mathrm{Na} A B$, essas ações devem compor o rol de açóes que compreendem o cuidado em saúde, com vistas à promoção, prevenção, tratamento e reabilitação dos agravos. Toda equipe pode e deve contribuir, de maneira efetiva e promovendo modos de vida mais saudáveis, sempre tendo em vista o empoderamento dos indivíduos e a promoção do autocuidado.

\section{Consideraçóes finais}

O Brasil é uma referência internacional nos marcos para a promoção da alimentação saudável e na organização das açóes de cuidado na Atenção Básica. As recomendações e práticas de PAAS 
devem romper a barreira da Atenção Básica e alcançar os demais pontos da Rede de Atençáo à Saúde a fim de qualificar o cuidado e harmonizar as informaçôes ofertadas aos usuários do SUS. Outro fator importante para impulsionar as ações é ampliar as parcerias tanto com outros equipamentos sociais como com outros atores do território que podem potencializar a PAAS.

Tornar a PAAS uma ação cotidiana não é uma tarefa fácil. Muitas são as barreiras para esse processo: fatores sociais, econômicos e políticos impactam nesse objetivo, além do fato de que a PAAS não está na agenda geral dos gestores de saúde. Seu sucesso depende da persistência dos trabalhadores que acreditam no potencial das ações para mudar as práticas de gestores e de trabalhadores, até que essas ações passem a ser incorporadas nas atividades cotidianas e na prática do cuidado como um todo.

\section{Referências}

BOOG, M. C. F. "Atuação do nutricionista em saúde pública na promoção da alimentação saudável”. Revista Ciência \& Saúde, v. 1, n. 1, pp. 33-42, 2008.

BRASIL. Casa Civil. Lei n. ${ }^{\circ}$ 8.080, de 19 de setembro de 1990. Dispóe sobre as condiçôes para a promoção, proteção e recuperação da saúde, a organização e o funcionamento dos serviços correspondentes e dá outras providências. Diário Oficial da união, v. 128, n. 182, 1990.

- Departamento de Atenção Básica. Política nacional de alimentação e nutrição. Brasília: Editora MS, 1999.

. Ministério da Saúde. Secretaria de Vigilância em Saúde. Política nacional de promoção da saúde. Brasília: Ministério da Saúde, 2006.

. Ministério da Saúde. Guia alimentar para a populaçáo brasileira: promovendo a alimentação saudável. Brasília: Editora MS, 2006a.

. Ministério da Saúde. Dialogando sobre o Direito Humano à Alimentação Adequada no contexto do SUS. Brasília: Editora MS, 2010.

. Ministério da Saúde. Política Nacional de Alimentação e Nutrição. 2 ed. Brasília: Editora MS, 2012a.

. Ministério do Desenvolvimento Social e Combate à Fome. Marco de referência de educação alimentar e nutricional para as políticas públicas. Brasília: Editora MDS, 2012b. 
- Ministério da Saúde. Secretaria de Atenção à Saúde. Departamento de Atenção Básica. Guia alimentar para a população brasileira. Brasília: Ministério da Saúde, 2014a.

. Portaria n. ${ }^{\circ}$ 2.446, de 11 de novembro de 2014. Redefine a Política Nacional de Promoção da Saúde (PNPS). Diário Oficial da União, 2014b.

. Ministério da Saúde. Secretaria de Atenção Primária. Departamento de Promoção da Saúde. Guia alimentar para crianças brasileiras menores de 2 anos. Brasília: Ministério da Saúde, 2019.

BUSATO, M. A. et al. "Ambiente e alimentação saudável: percepçôes e práticas de estudantes universitários". Semina: Ciências Biológicas e da Saúde, v. 36, n. 2, pp. 75-84, 2015.

CAMOZZI, A. B. Q. et al. "Promoção da Alimentação Saudável na Escola: realidade ou utopia?”. Cadernos Saúde Coletiva, v. 23, n. 1, pp. 32-7, 2015.

CAMPOS, G. W. S. "Saúde pública e saúde coletiva: campo e núcleo de saberes e práticas”. Ciência \& Saúde Coletiva, v. 5, n. 2, pp. 219-30, 2000.

CARVALHO, M. C. V. S. et al. "Comer, alimentar e nutrir: categorias analíticas instrumentais no campo da pesquisa científica”. Ciência \& Saúde Coletiva, v. 16, pp. 155-63, 2011.

DA SILVA OLIVEIRA, M. S. e SILVA-AMPARO, L. "Food-based dietary guidelines: a comparative analysis between the Dietary Guidelines for the Brazilian population 2006 and 2014”. Public Health Nutrition, pp. 1-8, 2017. FEUERWERKER, L. C. M. e CAPOZZOLO, A. A. "Mudanças na formação dos profissionais de saúde: alguns referenciais de partida do eixo trabalho em saúde". CAPOZZOLO A. A. et al. (orgs.). Clínica comum: itinerários de uma formação em saúde. Sáo Paulo: Hucitec, pp. 35-68, 2013.

FREITAS, M. C. S. et al. "Sobre o campo da Alimentação e Nutrição na perspectiva das teorias compreensivas". Ciência \& Saúde Coletiva, v. 16, pp. 31-8, 2011.

GARCIA, R. W. D. "Representações sociais da alimentação e saúde e suas repercussôes no comportamento alimentar". Physis: revista de saúde coletiva, v. 7 , pp. 51-68, 1997.

LINDEMANN, I. L. e MENDOZA-SASSI, R. A. "Orientação para alimentação saudável e fatores associados entre usuários da atenção primária à saúde no sul do Brasil". Revista Brasileira em Promoção da Saúde, v. 29, n. 1, pp. 34-42, 2016.

MALTA, D. C. et al. "O SUS e a Política Nacional de Promoção da Saúde: perspectiva resultados, avanços e desafios em tempos de crise”. Ciência \& Saúde Coletiva, v. 23, pp. 1799-809, 2018. 
MONTEIRO, C. A. et al. "Dietary guidelines to nourish humanity and the planet in the twenty-first century. A blueprint from Brazil". Public health nutrition, v. 18, n. 13, pp. 2311-22, 2015.

PELICIONI, M. C. F. e PELICIONI, A. F. "Educação e promoção da saúde: uma retrospectiva histórica". Mundo da saúde, v. 31, n. 3, pp. 320-8, 2007.

RAMOS, F. P. et al. "Educação alimentar e nutricional em escolares: uma revisão de literatura”. Cadernos de Saúde Pública, v. 29, pp. 2147-61, 2013.

SAQUET, M. A. e DA SILVA, S. S. "Milton Santos: concepçóes de geografia, espaço e território/Milton Santos: Geographyconceptions, spaceandterritory". Geo UERJ, v. 2, n. 18, pp. 24-42, 2011.

WHO, Joint e CONSULTATION, FAO Expert. Diet, nutrition and the prevention of chronic diseases, n. i-viii, 2003. (World Health Organization Technical Report Series, v. 916). 